(2) Open Access Full Text Article

ORIGINAL RESEARCH

\title{
Immersive placement experiences promote rural intent in allied health students of urban and rural origin
}

This article was published in the following Dove Press journal:

Journal of Multidisciplinary Healthcare

\section{Rebecca Wolfgang' \\ Luke Wakely' \\ Tony Smith ${ }^{2}$ \\ Julie Burrows' \\ Alexandra Little' \\ Leanne J Brown'}

'Tamworth Education Centre, University of Newcastle Department of Rural Health, Tamworth, NSW 2340, Australia; ${ }^{2}$ Manning Education Centre, University of Newcastle Department of Rural Health, Taree, NSW 2430, Australia
Correspondence: Rebecca Wolfgang Tamworth Education Centre, University of Newcastle Department of Rural Health, I I4-I 48 Johnston Street, Tamworth, NSW 2340, Australia

Tel +6I 267553515

Fax +61267612355

Email rebecca.wolfgang@newcastle.edu.au
Introduction: Pre-vocational placement experiences are known to considerably influence the career preferences of health graduates and are a key factor in growing the rural allied health workforce. This paper explores the rural placement experiences and future work intentions of students who attended a placement with the University of Newcastle Department of Rural Health.

Methods: Part of a larger longitudinal mixed methods study of students' placement experiences and subsequent career choices, this study explored students' placement evaluations responses. Following each placement, students were invited to complete an online survey which asked about their placement experiences and future work intentions. Counts and proportion tests were performed for frequencies of quantitative variables. Wilcoxon signed rank tests were conducted on the paired pre- and post-rural intent scores to determine any perceived differences in intent before and after placement for students both with and without a rural background. Qualitative data from short answer questions were analyzed thematically guided by qualitative content analysis. Data were comparatively analyzed for students of a rural or urban background.

Results: Four hundred and forty end of placement surveys were completed by 275 students (response rate $69.8 \%$ ). There was a positive shift in intention to work rurally for students of both rural and urban background post-placement, but this was only statistically significant in the group from an urban background $(p \leq 0.001)$. From the qualitative analysis three themes emerged: immersed rural supported placement experience, immersed interaction in rural life with other students, and immersed interaction in the rural community. Students from both rural and urban backgrounds indicated similar benefits and challenges.

Conclusion: While the positive impact of rural placement experiences and rural background on future rural practice is well known, this study highlights the importance of positive supported placement experience for students from both rural and urban backgrounds.

Keywords: rural health services, student placements, mixed method, career intentions, Australia

\section{Introduction}

It is well known that the disparity in health workforce distribution between metropolitan and rural areas is one of the contributing factors to the relatively poor health status of the non-metropolitan population in Australia due to the unique challenges of distance and geographic isolation. ${ }^{1,2}$ A major strategy of the Australian Commonwealth Government to address this disparity has been the funding and development of the Rural Health Multidisciplinary Training (RHMT) Program. ${ }^{2,3}$ 
The RHMT Program includes specific parameters that include: the delivery of effective rural training experiences for medical, dental, nursing, and allied health students; support of the existing local rural health workforce, and engagement and health promotion with the local community.

The University of Newcastle Department of Rural Health (UONDRH) is one of 16 University Departments of Rural Health (UDRHs) funded under the RHMT program and has education hubs throughout northern New South Wales. ${ }^{4}$ The main aim of UDRHs is to build future rural health workforce capacity by encouraging recruitment of new graduate health professionals and supporting their professional development, so that they stay and practice in rural and remote locations over extended periods of their career.

The UONDRH supports undergraduate rural health educational opportunities for allied health students from various disciplines to undertake a rural experience that incorporates their required professional practice placements in the local area. Rural options range from short-term placements of between 2- and 8-weeks duration, up to long-term attachments of a full semester or a full academic year of study. During the long-term attachments, (available to students in diagnostic radiography, nuclear medicine, nutrition and dietetics, occupational therapy, physiotherapy, radiation science, and speech pathology), students complete both their academic coursework and professional practice placement requirements of their studies remote from the main metropolitan campus.

The UONDRH employs a range of allied health academics to provide discipline-specific support to students in the form of lectures and tutorials, co-ordinate clinical placements, develop and deliver interprofessional education, and facilitate rural-focused community engagement and social activities, as well as undertake and support research. ${ }^{5}$ The UONDRH community engagement program supports students on placement in the region to learn from and with the local community, particularly with those from a low socioeconomic and/or Indigenous background. $^{6}$

While students' practice-based experience is predominantly profession specific, they are able to access subsidized accommodation and study in a multidisciplinary rural environment. The intention of having students living, studying, and working together is to increase their understanding of rural health issues and improve their appreciation of rural practice. It is considered that this enriching immersive experience may influence their openness to work rurally in the future and possibly contribute to improving the rural/urban workforce disparity. ${ }^{7}$

Among the factors that influence rural practice intentions for health students are; rural background, previous rural placement experience (including placement duration, rural lifestyle, supervisor attitudes, accommodation availability, relocation costs) and rural content of undergraduate curricula. $^{8-11}$ A perceived narrow range of patient contact and relevant learning opportunities are factors which have influenced students to choose not to undertake a rural placement. ${ }^{12-14}$ There is evidence that rural background is one of the more influential factors on students' perceptions of rural practice and likelihood of later rural practice ${ }^{10,15}$ yet, the impact of exposure to quality rural experiences for students of both rural and urban background should not be underestimated. $^{15,16}$

In a study of over 3300 students who participated in UDRH-supported placements across Australia, those who reported high levels of satisfaction with their placement experiences were 2.3 times more likely to indicate a future rural practice intention. ${ }^{17}$ It is further suggested that successful and satisfying UDRH placement experiences have the potential to launch students on a pathway to "ruralization", a construct that represents their integration into rural practice and lifestyle. $^{18}$

While much of the attention has been on influencing the practice intentions of medical students and early career practitioners, ${ }^{10,15,19,20}$ it is also important to target students and graduates of other health professions. There is a cogent argument that fully meeting the health care needs of underserved non-metropolitan populations requires a broad-based approach to recruitment and retention strategies that target a range of health professional students and graduates. $^{2}$ Yet, to date there have been few studies that investigate the experiences of allied health students during undergraduate rural placements and the impact of these placements on their practice intentions following graduation. ${ }^{9,17,21}$

Given the apparent lack of evidence and gap in the literature, the UONDRH study evaluating allied health students' rural placement experience and postgraduate workplace outcomes was developed as a means of contributing to this. ${ }^{7}$ This paper reports on the undergraduate immersive placement experiences of UONDRH allied health students. The main aim was to determine the effect of their immersive placement experience on their rural 
practice intentions and to compare outcomes between students from a rural vs an urban background.

\section{Methods}

This is an ongoing longitudinal study, that uses mixed methodology to evaluate allied health students' placement experiences and track their career outcomes, through data collection from an end of placement (EOP) survey, semistructured individual interviews, and postgraduate surveys. The detailed methods for this study have been described previously. ${ }^{22}$ Data analyzed for this paper were collected from the EOP surveys and specific methods relevant to the data collection for this paper are described below.

\section{Participants}

Students who participated in the study were from the University of Newcastle and were enrolled in undergraduate bachelor degree programs of medical radiation science (which includes diagnostic radiography, nuclear science, and radiation science), nutrition and dietetics, occupational therapy, physiotherapy, and speech pathology who undertook placements at the UONDRH between May 2011 and June 2016. Students from the disciplines of speech pathology and occupational therapy were also included from 2012. Students undertaking semester or year-long attachments chose their placement location and students undertaking short-term placements were allocated the placement location based on their preferences. All eligible students were invited to participate in the study by a research assistant during their UONDRH placement orientation at the key sites of Tamworth and Taree.

\section{End of placement survey}

All students undertaking a rural placement in a UONDRH site are asked to complete an EOP survey at the conclusion of their placement. Where individual students undertook multiple placements across their degree, evaluations were completed for each individual placement. Study participants were asked to consent to their EOP survey data being used as part of this study. The survey consisted of 21 questions used by all UDRHs to characterize the national student cohort involved in regional, rural or remote placements, to evaluate their experiences and degree of satisfaction with their placement and determine if this has influenced their perceptions of living and working in a non-metropolitan location. In addition, a further 16 questions targeted specific local aspects of the UONDRH students' educational and lifestyle experiences while on placement. The survey was provided online via Survey Monkey (https://www.surveymonkey.com/) and responses were downloaded automatically into a Microsoft Excel spreadsheet.

Changes were made to the EOP survey in 2014. Whilst much of information captured by the revised survey was the same as the original survey, the response scale descriptors to some questions changed. One such question was "Overall, how would you rate your satisfaction with your placement?" with responses on a 5-point Likert scale ranging from "Strongly Agree" to "Strongly Disagree" being introduced, replacing "Excellent" to "Undecided".

Rural practice intention was also measured on a 5-point Likert scale in response to two statements. The first question asked, "Prior to this placement I was considering living and working in a regional, rural or remote location following graduation". The second statement asked the student to consider the impact of their placement on their consideration of rural practice by asking: "This placement has made me reconsider my future and I am now considering living and working in a regional, rural or remote location following my graduation".

Data reported below include student participants' demographic details relating to gender, discipline studied and year of study, satisfaction with placement, and students' considerations for working rurally following graduation prior to and following placement. It also describes the student participants' responses to open-ended questions (see Figure 1) about their placement experiences. Rural background was self-reported by students in response to the survey question, "Have you previously lived in a rural area".

\section{Data analysis}

The survey data were imported into IBM SPSS software (https://www.ibm.com/analytics/spss-statistics-software). Counts and proportion tests were performed for frequencies of variables including gender, discipline, year of study, and satisfaction with placement. Rural background was cross-tabulated with consideration to work rurally before (retrospectively) and after placement. Wilcoxon Signed Ranks tests were conducted on the paired preand post-rural practice intention scores to determine if there were differences before and after placement for students both with rural and without a rural background. The overall effect of placements on students' rural practice intention was determined by subtracting the post from the pre-placement score (paired data). The Mann- 
- What were the things you enjoyed most about your placement?

- Briefly describe your experiences of living and working at your placement location

- Do you have any suggestions to improve these placements?

- Do you have any further comments?

- We are interested in capturing information on opportunities for interaction with rural community members, other health professionals and students. Briefly describe your experiences of meeting / socialising with other students, health professionals and community members while on your placement?

- The things that I LEAST enjoyed about my placement at this location were...

Figure I Short answer questions from the end of placement survey.

Whitney U test was used to compare the effect of placement on the rural practice intention of students from rural and urban backgrounds.

Responses to open-ended questions about placement experiences were analyzed using qualitative content analysis. $^{23,24}$ Student participant responses were initially inductively assigned code of meaning by two researchers separately (RW and LW). These codes were then reflected on and gradually developed into thematic categories. Emerging analysis was compared with the student participants' open-ended responses to ensure that the thematic ideas were reflected in the data. NVivo software (QSR International; http://www.qsrinternational.com) was used to assist with data management. Rigor of the analysis was established through a range of strategies guided by the terms proposed by Lincoln, $\mathrm{Guba}^{25}$ Credibility was enhanced by discussing the emerging analysis with all members of the research team. The research team consisted of researchers representing each of the health disciplines included in the study, thus discipline-specific nuances in the data could be clarified and understood. Transferability was ensured by collecting demographic data and reporting this in as much detail as possible, while conscious of maintaining the anonymity of participants. Dependability was established by documenting and reflecting on, the conceptual decisions and notions that emerged during data analysis. Confirmability was ascertained by regularly reviewing the original data to ensure that the emerging interpretation was reflected in the data and by using direct quotes to illustrate aspects of the analysis.

\section{Ethics approval}

This study has ethical approval (approval number: H-20110027) from The University of Newcastle Human Research Ethics Committee.

\section{Results}

Between May 2011 and June 2016, 484 of 526 (92.0\%) eligible allied health students were formally invited to participate in the study. Three hundred and ninety-four (81.4\%) students consented to their EOP survey data being used as part of the study, and 275 of the consenting students completed at least one survey; a response rate of $69.8 \%$.

\section{Quantitative data analysis}

Student participant demographic data are presented in Table 1 . The majority of students $(62.7 \%)$ were in their fourth (final) year of study and 128 (46.5\%) had never lived in a rural location prior to undertaking their placement. Physiotherapy students represented the largest proportion of students $(34.2 \%)$, followed by nutrition and dietetics (28.4\%). There were 440 EOP surveys completed by 275 students. One hundred and twenty-one students completed the survey on more than one occasion, as they undertook more than one professional practice placement in the same year or different years across the UONDRH footprint. Table 2 provides a summary of placement location, placement length, and student placement satisfaction. The majority $(55.3 \%)$ of students undertook a placement of 5-12 weeks and $19.6 \%$ of the students spent an extended 6-12 months in their immersive placement location. The placement locations were located in sites classified as 3-5 under the Modified Monash Model (MMM) rurality classifications, with the majority $(97.5 \%)$ based in MMM3. The majority of students $(97.3 \%)$ reported satisfaction with placement as "Good", "Excellent", or "Agree" and "Strongly Agree".

\section{Rural practice intention}

Pre- and post-placement rural practice intention scores from the EOP survey were completed for 271 (98.5\%) of the 
Table I Demographic data for students who completed the endof-placement survey between $201 \mathrm{I}$ and 2016 and were included in the study

\begin{tabular}{|l|l|}
\hline Individual (n=275) & n (\%) \\
\hline Gender & \\
Male & $50(18.2)$ \\
Female & $227(81.8)$ \\
\hline Discipline & \\
Medical Radiation Science ${ }^{\mathrm{a}}$ & $32(1 \mathrm{I} .6)$ \\
Nutrition and Dietetics & $78(28.4)$ \\
Occupational Therapy & $32(11.6)$ \\
Physiotherapy & $94(34.2)$ \\
Speech Pathology & $39(14.2)$ \\
\hline Rural background & \\
I0 years or more & $110(40.0)$ \\
6-9 years & $12(4.4)$ \\
3-5 years & $11(4.0)$ \\
I-2 years & $4(1.5)$ \\
Less than I year & $10(3.6)$ \\
Never & $128(46.5)$ \\
\hline
\end{tabular}

Notes: ${ }^{a}$ Occupational therapy and speech pathology students were included from 2012 onwards. 'Medical Radiation Science includes the disciplines of; diagnostic radiography, nuclear medicine, and radiation science.

student participants, as four students did not provide both intention scores. Of these, 160 (59.0\%) considered working rurally before placement (urban $\mathrm{n}=52,40.9 \%$; rural $\mathrm{n}=108$, $75.0 \%$ ) and $203(74.9 \%$ ) following placement (urban $n=89$, $70.1 \%$; rural $n=114,79.2 \%$ ) (refer to Table 3 ). The majority of students $(52.4 \%)$ had a positive rural practice intention both before and after placement. Ninety-nine (36.5\%) respondents reported they would give more consideration to working in a rural location after placement (urban $n=69$, $54.3 \%$; rural $\mathrm{n}=30,20.8 \%$ ). Twenty-eight (urban $\mathrm{n}=10$, $7.9 \%$ : rural $n=19,13.2 \%$ ) respondents reported they would give less consideration toward rural practice after placement. Of the 28, 10 remained positive in their attitude toward rural practice following placement (moving from "Strongly Agree" to "Agree") and 17 moved from a positive to a neutral attitude. One respondent (urban background) shifted from a positive to a negative attitude and one respondent remained negative toward rural practice.

The mean scores for rural practice intention were higher for students of both rural and urban background after placement, indicating a shift to a more favorable attitude toward rural practice overall, however, the difference in scores before and after placement was only statistically significant in the group from an urban background $(p \leq 0.001)$.
Figure 2 represents the effect of placement on rural intent scores for students from rural and urban backgrounds. The distribution of effect scores for each group is significantly different with the effect skewed toward a more positive effect for urban students $(p \leq 0.001)$. Change in rural practice intention was significant across all placement lengths and disciplines, except for medical radiation science (refer to Table 4).

\section{Qualitative data analysis}

The qualitative content analysis illuminated three themes: Immersed rural supported placement experience; Immersed interaction in rural life with other students; and, Immersed interaction in the rural community. Each is described below, with illustrative quotations from the open-ended responses to the survey.

\section{Immersed rural supported placement experience}

Describes students' responses about the quality of supervision and clinical experiences they received while on their rural professional practice placement. It also refers to the additional support from the rurally based UONDRH academic staff. Students from both urban and rural backgrounds spoke positively of the opportunity to experience the breadth of rural clinical practice during their placements. As one nutrition and dietetic student of rural origin wrote, "I enjoyed the wide variety of clinical cases seen because of the rural environment". This was echoed by a speech pathology student of urban origin, "I enjoyed the different caseloads we were exposed to, the clients and families I got to meet, and I also enjoyed the outreach services provided to communities".

The students also reported receiving high-quality supervision from their placement supervisors whom they perceived as invested in providing an enriching experience for students. As one physiotherapy student of rural origin reported:

One of the main reasons for why I enjoyed my placement [was] due to my clinical educator. She is one of the most patient people I know. She explains concepts so well to myself and also to the people that she is treating on the ward. I believe that my experience made me a better physiotherapist and has encouraged me further into working in a rural health setting. [Physiotherapy student of rural origin]

This was reaffirmed by students of urban origin, such as one speech pathology student who commented, "I enjoyed the supportive nature of the placement and the supportive learning environment, the supervisors are willing to go above and 
Table 2 Rural placement location, placement length, and student satisfaction with placement

\begin{tabular}{|c|c|c|c|c|}
\hline Individual surveys $(n=440)$ & Site population ( 2016 census data) & MMM classification & ASGC-RA & n (\%) \\
\hline \multicolumn{5}{|l|}{ Placement location } \\
\hline Armidale & 23,352 & 3 & RA2 & $22(5)$ \\
\hline Forster & 14,267 & 3 & RA2 & $6(1.4)$ \\
\hline Inverell; Gunnedah: Bingara ${ }^{a}$ & II,660; 9726; 1428 & $4 ; 4 ; 5$ & RA3 & $3(0.7)$ \\
\hline Moree & 9311 & 4 & RA3 & $6(1.4)$ \\
\hline Port Macquarie & 44,830 & 3 & RA2 & $10(2.3)$ \\
\hline Quirindi & 3444 & 5 & RA3 & $2(0.4)$ \\
\hline Tamworth & 41,189 & 3 & RA2 & $275(62.5)$ \\
\hline Taree & 20,482 & 3 & RA2 & III (25.2) \\
\hline Wingham & 5374 & 3 & RA2 & $3(0.7)$ \\
\hline No response & $\mathrm{N} / \mathrm{A}$ & $\mathrm{N} / \mathrm{A}$ & $\mathrm{N} / \mathrm{A}$ & $2(0.4)$ \\
\hline \multicolumn{5}{|c|}{ Year of study at time of completing survey } \\
\hline$I^{\text {st }}$ year & & & & $8(1.8)$ \\
\hline $2^{\text {nd }}$ year & & & & $69(15.7)$ \\
\hline $3^{\text {rd }}$ year & & & & $81(18.4)$ \\
\hline $4^{\text {th }}$ year & & & & $276(62.7)$ \\
\hline $5^{\text {th }}$ year ${ }^{b}$ & & & & $6(1.4)$ \\
\hline \multicolumn{5}{|c|}{ Satisfaction with placement Original survey $n=259$} \\
\hline Excellent & & & & $174(67.2)$ \\
\hline Good & & & & $78(30.1)$ \\
\hline Poor & & & & $2(0.8)$ \\
\hline Undecided & & & & $4(1.5)$ \\
\hline No response & & & & $\mathrm{I}(0.4)$ \\
\hline \multicolumn{5}{|l|}{ Revised survey $n=|8|$} \\
\hline Strongly Agree & & & & $114(63.0)$ \\
\hline Agree & & & & $62(34.3)$ \\
\hline Neutral & & & & $4(2.2)$ \\
\hline Disagree & & & & 0 \\
\hline Strongly Disagree & & & & 0 \\
\hline No response & & & & $\mathrm{I}(0.5)$ \\
\hline \multicolumn{5}{|c|}{ Rural placement attachment length } \\
\hline I-2 weeks & & & & $3(1.1)$ \\
\hline 3-4 weeks & & & & $47(17.1)$ \\
\hline 5-12 weeks & & & & $152(55.3)$ \\
\hline 3-6 months & & & & $19(6.9)$ \\
\hline $6-12$ months & & & & $54(19.6)$ \\
\hline
\end{tabular}

Notes: ${ }^{a}$ Data pooled to preserve anonymity. ${ }^{b}$ Programs do not include a 5 th year, but a number of students reported they were in their 5 th year of study. Abbreviations: MMM, Modified Monash Model; ASGC-RA, Australian Standard Geographical Classification- Remoteness Area.

beyond to help you". Students received additional support from rurally based academic staff and were grateful for this support:

I felt very well supported by [local academic staff], and although I didn't require any assistance, other OT students at other sites did. [The academic occupational therapist] was able to maximise their learning opportunities in difficult circumstances and provided them with excellent support from someone outside of their clinical placement site. This was very valuable for those students who had difficulties! [Occupational therapy student of rural origin]

The UONDRH initiative supports clinical educators so they are able to provide quality student supervision. The local academics are able to nurture the students' learning, support the placement supervisors and work closely with the academics at the main campus of the university. 
Table 3 Students' rural practice intention before and after placement by background

\begin{tabular}{|c|c|c|c|c|}
\hline \multirow[t]{2}{*}{ Background } & \multirow[t]{2}{*}{ Likert response } & \multicolumn{2}{|c|}{ Rural practice intention, $\mathbf{n}(\%)^{a}$} & \multirow[t]{2}{*}{$p$-Value* } \\
\hline & & Before $^{b}$ & After ${ }^{c}$ & \\
\hline Urban $(n=127)$ & $\begin{array}{l}\text { Strongly Agree (5) } \\
\text { Agree (4) } \\
\text { Neutral (3) } \\
\text { Disagree (2) } \\
\text { Strongly Disagree (I) } \\
\text { Mean score (SD) }\end{array}$ & $\begin{array}{l}8(6.3) \\
44(34.6) \\
29(22.8) \\
37(29.1) \\
9(7.1) \\
3.04(1.087)\end{array}$ & $\begin{array}{l}28(22.0) \\
61(48.0) \\
27(21.3) \\
8(6.3) \\
3(2.4) \\
3.81(0.932)\end{array}$ & $<0.001$ \\
\hline Rural $(n=\mid 44)$ & $\begin{array}{l}\text { Strongly Agree (5) } \\
\text { Agree (4) } \\
\text { Neutral (3) } \\
\text { Disagree (2) } \\
\text { Strongly Disagree (I) } \\
\text { Mean score }\end{array}$ & $\begin{array}{l}55(38.2) \\
53(36.8) \\
24(16.7) \\
9(6.3) \\
3(2.1) \\
4.03(0.996)\end{array}$ & $\begin{array}{l}52(36.1) \\
62(43.1) \\
28(19.4) \\
2(1.4) \\
0(0) \\
4.14(0.772)\end{array}$ & 0.063 \\
\hline
\end{tabular}

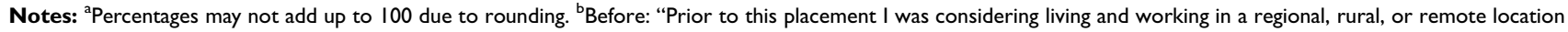
following graduation." 'After: "This placement has made me reconsider my future and I am now considering living and working in a regional, rural, or remote location following my graduation." *Wilcoxon Signed Ranks Test.

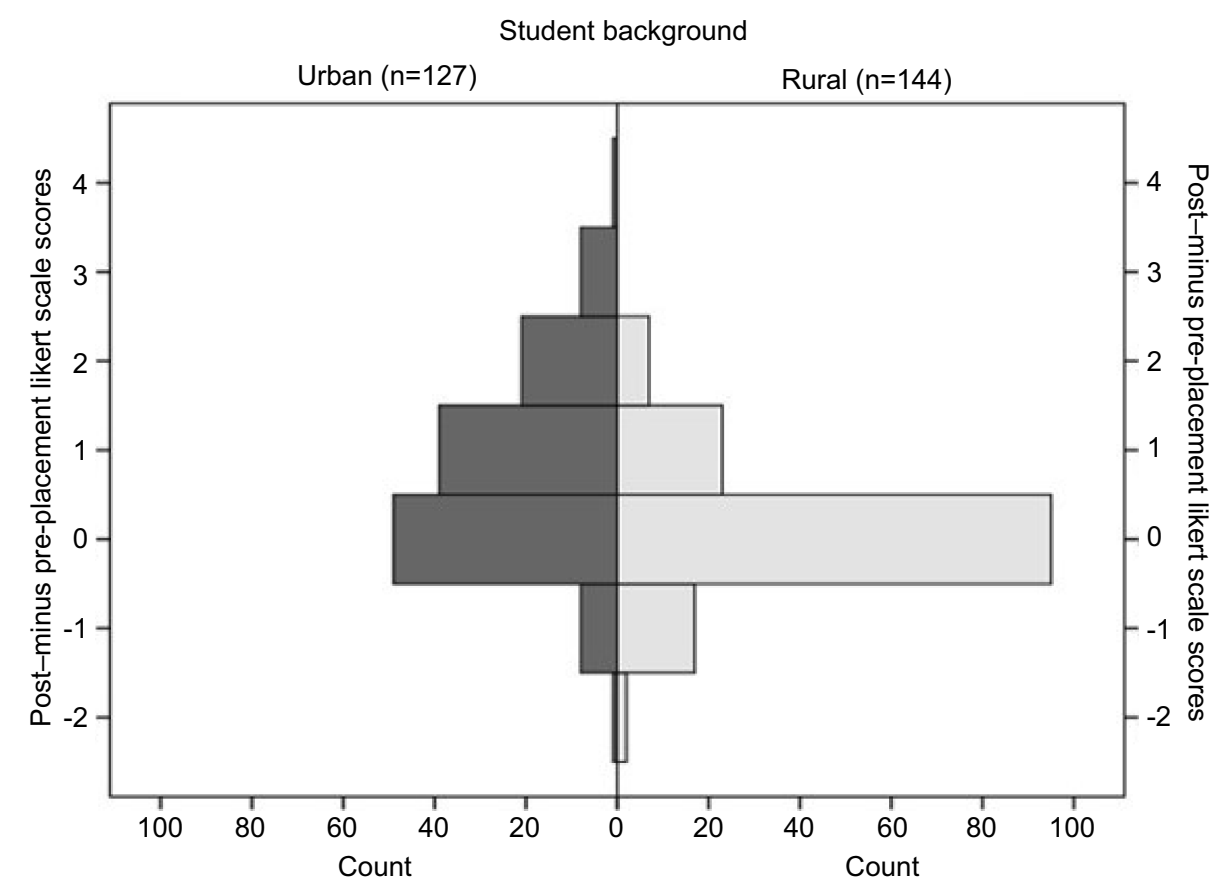

Figure 2 The effect of placement on the difference between pre- and post-placement rural practice intention scores for rural vs urban background students ( $p<0.00 \mathrm{I}$ ).

Immersed interaction in rural life with other students Refers to how participating in learning and social activities, as well as being co-located in the UONDRH accommodation promoted a sense of community and interdisciplinary comradery between the students. The students found they developed connections with other students as reported by a medical radiation science student of urban origin, "living with health students of other disciplines helped to broaden my understanding of patient care and the healthcare team". The positive impact of the accommodation on the placement experience was also commented on by a speech pathology student of urban origin, "The accommodation and social aspect were great and I liked how my accommodation was super close to my 
Table 4 Students' rural practice intention before and after placement by discipline and placement length

\begin{tabular}{|c|c|c|c|c|c|}
\hline & & \multirow[t]{2}{*}{ Number of participants } & \multicolumn{2}{|c|}{ Mean rural practice intention score (SD) ${ }^{a}$} & \multirow[t]{2}{*}{$p$-Value* } \\
\hline & & & Before $^{b}$ & After ${ }^{c}$ & \\
\hline \multirow[t]{5}{*}{ Discipline } & Physiotherapy & 91 & $3.29(1.204)$ & $3.85(0.893)$ & $<0.001$ \\
\hline & Nutrition and dietetics & 77 & $3.49(1.096)$ & $4.01(0.866)$ & $<0.001$ \\
\hline & Occupational therapy & 32 & $3.72(1.301)$ & $4.06(1.014)$ & 0.048 \\
\hline & Speech pathology & 39 & $3.85(0.904)$ & $4.15(0.709)$ & 0.018 \\
\hline & Medical radiation science & 32 & $4.03(1.031)$ & $4.03(0.782)$ & 0.971 \\
\hline \multirow[t]{4}{*}{ Placement Length } & Less than 4 weeks & 47 & $3.50(1.035)$ & $3.84(0.792)$ & 0.003 \\
\hline & 5-12 Weeks & 152 & $3.36(1.173)$ & $3.86(0.908)$ & $<0.001$ \\
\hline & 3-6 Months & 19 & $3.74(1.046)$ & $4.26(0.733)$ & 0.046 \\
\hline & 6-12 Months & 54 & $4.11(1.058)$ & $4.35(0.73 \mathrm{I})$ & 0.022 \\
\hline
\end{tabular}

Notes: ${ }^{a}$ Likert Responses: Strongly Disagree (I), Disagree (2), Neutral (3), Agree (4), Strongly Agree (5). 'Before: "Prior to this placement I was considering living and working in a regional, rural, or remote location following graduation." 'After: "This placement has made me reconsider my future and I am now considering living and working in a regional, rural, or remote location following my graduation." *Wilcoxon Signed Ranks Test.

placement location". This support was also important for students of rural origin as they too are often away from the familiarity of home. A speech pathology student of rural origin spoke of the informal peer support that helped her manage living away from home while undertaking her placement:

I loved living with other students. It's hard to move away from all your supports and networks for six weeks and not feel home sick. I think I was too busy and stressed to feel homesick, but I think this also had something to do with the support I got from the other students living at the [accommodation] with me. [Speech pathology student of rural origin]

This was echoed by urban origin students. For example, a physiotherapy student stated that they “ ... also enjoyed getting to know my other peers very well, we spent nearly every afternoon and all weekend exploring different areas of the region that we had never seen before". Although in smaller outlying sites where there was one student on placement at the time, this could potentially be isolating, as a physiotherapy student of urban origin stated, "two people on prac would have been better than one". This demonstrates how co-location with other students can be a positive support if away from usual supports such as family and friends. In addition to providing co-location with other students, the accommodation at the UONDRH is subsided increasing affordability for students who otherwise may have found it difficult to re-locate for a rural placement. One nutrition and dietetic student of urban origin explained, "the accommodation was really great, and the subsidy meant that it was financially possible for me to do a rural placement". Providing subsidized placement accommodation reduced a potential stressor experienced by students living away from home.

Much of this interaction between the students is facilitated rather than opportunistic in nature. UONDRH students are engaged in a range of formal and informal interprofessional and social activities while on placement. These aim to broaden the students' understanding of the roles of a range of health disciplines, and how they work together in the context of rural health care, as well as helping them develop social and professional networks while on placement and beyond. A number of students expressed they would have liked more social opportunities during their placement. A speech pathology student of rural origin stated, "Should have more access to social activities with other students". This investment into developing their skills and networks appeared to be a highlight of many rural and urban origin students' experiences. As one nutrition and dietetic student of rural origin wrote, "there is a focus on interprofessional learning, developing networks and readying everyone for future employment, and also getting the most out of everyone". A speech pathology student of urban origin described how she:

\footnotetext{
... was able to meet various health professionals when participating in tutorials, interprofessional learning modules, and the allied health camp. This also put me into contact with other students where I was able to learn more about their disciplines. [Speech pathology student of urban origin]
}

Most UONDRH students are co-located and supported in getting to know each other and learning to work with each other. This is a novel yet essential aspect of this rural program. Although the students are away from their 
usual support of family and friends, there is a culture of surrogate collegial support from other students.

\section{Immersed interaction with the rural community}

Is about students expressing that they were able to gain a sense of community and belonging while on placement despite being away from home. Students from both rural and urban origin expressed a sense of their placement extending beyond their clinical work to allow them to experience a rural lifestyle and culture. For example, one nutrition and dietetic student of urban origin reported, "Compared to a lot of city placements we were presented with a lot of opportunities to get involved in the community and feel a part of the community ..." and a physiotherapy student of rural origin stated, "I enjoyed the close-knit nature of a rural town". Students of urban origin reported enjoying the rural lifestyle experience, an experience that was typically novel for them. For example:

Living in Tamworth has been quite fulfilling, in that it has given me the experience of living and working in a rural area, which I have not done before. By working in a small town, there is an increased likelihood of knowing someone personally, either immediately or by mutual connection. [Nutrition and dietetic student of urban origin]

The students perceived that rural community members wanted to support them and make them feel welcome. As an occupational therapy student of urban origin described, "I honestly feel that people in rural areas may actually be more welcoming and willing to dedicate their time than they may in a metropolitan area". Many students formally participated in UONDRH facilitated community engagement activities. Students expressed that this was a valuable experience regardless of whether they were of rural or urban origin. As one nutrition and dietetics student from a rural area detailed, "I gained valuable professional experience and developed close working relationships and networks with many local community organizations and program participants". A speech pathology student of urban background related these additional opportunities enhanced the placement experience in a way that may not have been possible if on an urban-based placement.

The community engagement programs were great too, as I would not have had the opportunity to participate in these in a non-rural placement, it also helped me further my clinical skills as a future health graduate. [Speech pathology student of urban origin]
The opportunity to experience and learn about rural communities and the unique health challenges they face was consistently reported as an enriching aspect of the students' placement and a valued learning experience.

\section{Discussion}

Using qualitative and quantitative methodology, this indepth study adds to the limited literature regarding allied health student placement experiences of UDRH placements and their workplace intentions. ${ }^{6,9,17,18,21,26}$ The results provide insights into the immersive placement experiences of UONDRH allied health students and the effect on their rural practice intentions, comparing outcomes between those from a rural vs an urban background. The data indicate that across four of the five allied health bachelor degree programs, students' intentions to work rurally increased following their rural placement. There was no change in intention to work rurally for medical radiation science students as their intentions were high both before and after placement. These results are consistent with other studies which found exposure to a rural placement positively influenced students' attitudes toward working rurally. $5,8,27-32$

In this study, there was a positive shift in intention to practice rurally for students of both rural and urban origin following placement. This shift was more significant for students who had never lived in a rural area, which is contrary to other studies that demonstrated that students from a non-rural background are less likely to consider working rurally. ${ }^{9,15,33}$ The qualitative and quantitative data suggest that the UONDRH program and the immersive experiences it offers to students has more impact on the intentions to work rurally on those from an urban background. Previously reported findings suggest that positive rural placement experiences can be influenced at 1 year and 3 years after graduation. Of graduates from an urban background who were employed in a non-metropolitan location, $79 \%$ reported having been influenced by their rural placement when deciding to take-up their current position. ${ }^{22}$ Despite this significant positive shift in intention to practice rurally among students from an urban origin, three quarters of the students from a rural background gave consideration to work rurally prior to placement which increased post-placement. This is congruent with studies ${ }^{9,32}$ suggesting rural background is strongly associated with more positive perceptions of rural practice. Despite the evidence linking rural origin to intended rural practice, ${ }^{9,15,21,30,33,34}$ the importance of maintaining a 
focus on delivering high-quality rural placement experiences for all students regardless of origin cannot be underestimated.

Undertaking a rural placement alone is not an influential factor for future rural practice among students. Past community rural exposure ${ }^{21,30,33}$ awareness of the health needs of rural communities ${ }^{28}$ and a positive rural placement experience ${ }^{26,34}$ have been suggested as strong influencing factors in predicting students' intentions to consider rural employment. The high level of satisfaction indicated by students $(92 \%)$ in this study following a UONDRH-supported clinical placement and a strong intention to consider rural employment post-placement reinforces this link.

The UONDRH program aims to provide an immersive rural placement experience where students have the opportunity to integrate into rural communities and understand the unique health challenges they face. The study findings highlight that the community engagement activities undertaken by the students provide opportunities for this integration. Previous research findings suggest students have a better understanding of the nature of rural practice through integrating with the local community, particularly with rural people from low socioeconomic and Indigenous backgrounds. ${ }^{6}$ Integrating community engagement activities into the UONDRH program continues to have positive benefits. Students from urban origin were more likely to value their opportunities for connecting with the local rural community, compared to the rural origin students who, although enjoyed the experience, such experiences were not novel for them. This provides further evidence of the importance of engaging students from a non-rural background with rural communities to provide them the skills and confidence to work rurally as a future health graduate.

The barriers reported by health students to choose a rural placement include perceived narrow range of patient contact and learning opportunities and inferior quality of placement, distances from friends and social outlets, part-time job commitments, additional costs associated with staying away from home, and lack of accommodation. ${ }^{12-14}$ The experiences of students in this study suggest that these barriers are significantly lessened when undertaking a UONDRH supported placement. The affordable accommodation enabled the opportunity for students of both urban and rural origin to undertake a rural placement, where this may not have been possible otherwise. Co-location of students from different disciplines in the accommodation encouraged interdisciplinary exposure that was enriched through formalized interprofessional learning opportunities during their placement. The development of interprofessional networks beyond placement is essential for practicing in remote and rural locations. $^{18}$

Despite previous reports that students were reluctant to complete a rural clinical placement due to a perception of a narrow casemix, ${ }^{12-14}$ students of both rural and urban origin highlighted the breadth of clinical placement opportunities afforded to them. This is congruent with the understanding that rural clinical placements are often of a generalist nature and therefore arguably ideal for students to develop and consolidate clinical skills with a broad range of clinical presentations. ${ }^{35}$

Students reported appreciation for the high-quality clinical supervision they received in a supportive learning environment and exposing them to the breadth of rural practice. They also appreciated the support and mentoring provided by the UONDRH local academics as augmenting their clinical learning experiences. The linking role between the UONDRH local academics and the clinical supervisors is key to provide an enriching placement experience and developing an openness to future rural practice.

A strength of this research is the high response rate and sample of allied health students from a broad range of disciplines contributing to the existing limited literature exploring allied health student placement experiences. The mixed methodology offers both a broad and in-depth insight into students' responses, allowing an exploration of their rural placement experiences and the influences of these experiences on their placement satisfaction and rural practice intentions. There are also some acknowledged limitations to this study. A stronger study design would be to compare change in rural practice intention with students who did not undertake a rural placement. The students who consented to participate in the study may be more likely to be favorable of rural practice. Students' intentions to practice rurally prior to and following placement were completed at the end of the placement relying on their perceptions of their intention prior to commencing the placement. Students' intentions and consideration for rural practice does not mean that they will enter the rural allied health workforce. However, the strength of the longitudinal nature of this allied health student follow-up study is enabling the researchers to track the students 1-, 3-, and 5-years post-graduation to determine their workforce outcomes. 


\section{Conclusion}

This research data suggest that providing an immersive rural placement experience has a positive impact on students' intentions to practice rurally for both students of urban and rural origin. Learning in a supported environment enhanced by positive professional practice role models, creating a sense of belonging, understanding rural communities, and exposure to rural health issues facilitated an enriching placement experience for students that encouraged rather than discouraged, for most, the openness to rural practice in the future.

This study adds to the evidence by demonstrating the positive effects of a rural undergraduate placement on students' consideration for rural practice following graduation. The immersive rural experiences of students would suggest that what students "do" whilst they are on an immersive placement is a significant contributing factor to their positive intentions to rural practice, and preparing them for future practice in a non-metropolitan location.

While the focus to date has importantly been around the benefits of supported positive rural placement experiences for students of a rural origin, such experiences for students from both rural and urban origins may present a viable strategy for addressing the maldistribution of the current health workforce.

\section{Acknowledgments}

The source of funding for this research is via the Rural Health Multidisciplinary Training Program, which is administered by the Australian Government Department of Health. The authors also wish to acknowledge the contribution of students who participated in the study and the multidisciplinary team of staff. The authors declare that this manuscript or parts of its content are not currently under consideration or published in another journal.

\section{Author contributions}

All authors contributed to data analysis, drafting or revising the article, gave final approval of the version to be published, and agree to be accountable for all aspects of the work.

\section{Disclosure}

The authors report no conflicts of interest in this work.

\section{References}

1. Australian Institute of Health and Welfare. Australia's Health 2018 in Brief Cat. No AUS 222. Canberra: AIHW; 2018.

2. Wakerman J, Humpreys J. Sustainable workforce and sustainable health systems for rural and remote Australia. Med $J$ Aust. 2012;199(Suppl 5):14-17. doi:10.5694/mja11.11639

3. The Department of Health. Rural Health Multidisciplinary Training (RHMT) program. Australian government; Published 2018. Available from: http://www.health.gov.au/internet/main/publishing.nsf/content/ rural-health-multidisciplinary-training. Accessed August 7, 2018.

4. Australian Rural Health Education Network. UDRH Locations; Published 2019. Available from: http://arhen.org.au/about-urdhs/ urdh-locations/. Accessed January 18, 2019.

5. Smith T, Brown L, Cooper R. A multidisciplinary model of rural allied health clinical-academic practice: a case study. J Allied Health. 2009;38(4):237-242.

6. Fisher K, Smith T, Brown L, et al. Value-adding to health professional student placement experiences: enhancing work readiness and employability through a rural community engagement program. J Teach Learn Graduate Employability. 2018;9(1):41-61. doi:10.21153/jtlge2018vo19no1art698

7. Brown L, Smith T, Wakely L, Little A, Wolfgang R, Burrows J. Preparing graduates to meet the allied health workforce needs in rural Australia: short-term outcomes from a longitudinal study. Educ Sci. 2017;7(2):64. doi:10.3390/educsci7020064

8. Heaney SE, Tolhurst H, Baines SK. Choosing to practice in rural dietetics: what factors influence that decision? Aust J Rural Health. 2004;12(5):192-196. doi:10.1111/j.1440-1854.2004.00603.x

9. Playford D, Larson A, Wheatland B. Going country: rural student placement factors associated with future rural employment in nursing and allied health. Aust $J$ Rural Health. 2006;14(1):14-19. doi:10.1111/j.1440-1584.2006.00745.x

10. Playford D, Ngo H, Gupta S, Puddey IB. Opting for rural practice: the influence of medical student origin, intention and immersion experience. Med J Aust. 2017;207(4):154-158.

11. Tate RB, Aoki FY. Rural practice and the personal and educational characteristics of medical students. Can Fam Physician. 2012;58(11): e641. e648.

12. Barney T, Russell M, Clark M. Evaluation of the provision of fieldwork training through a rural student unit. Aust J Rural Health. 1998;6(4):202-207.

13. Deaville JA, Wynn-Jones J, Hays RB, Coventry PJ, McKinley RK, Randall-Smith J. Perceptions of UK medical students on rural clinical placements. Rural Remote Health. 2009;9(2):1165.

14. Smith S, Edwards H, Courtney M, Finlayson K. Factors influencing student nurses in their choice of a rural clinical placement site. Rural Remote Health. 2001;1(1):89.

15. Kondalsamy-Chennakesavan S, Eley DS, Ranmuthugala G, et al. Determinants of rural practice: positive interaction between rural background and rural undergraduate training. Med J Aust. 2015;202(1):41-45.

16. Walker JH, Dewitt DE, Pallant JF, Cunningham CE. Rural origin plus a rural clinical school placement is a significant predictor of medical students' intentions to practice rurally: a multi-university study. Rural Remote Health. 2012;12:1908.

17. Smith T, Sutton K, Pit S, et al. Health professional students' rural placement satisfaction and rural practice intentions: a national cross-sectional survey. Aust J Rural Health. 2018;26(1):26-32. doi:10.1111/ajr.12375

18. Smith T, Cross M, Waller S, et al. Ruralization of students' horizons: insights into Australian health professional students' rural and remote placements. J Multidiscip Healthc. 2018;11:85-97. doi:10.2147/JMDH. S150623

19. Brooks RG, Walsh M, Mardon RE, Lewis M, Clawson A. The roles of nature and nurture in the recruitment and retention of primary care physicians in rural areas: a review of the literature. Acad Med. 2002;77(8):790-798 
20. Jones M, Humphreys J, Prideaux D. Predicting medical students' intentions to take up rural practice after graduation. Med Educ. 2009;43(10):1001-1009. doi:10.1111/j.1365-2923.2009. 03506.x

21. Dalton LM, Routley GK, Peek KJ. Rural placements in Tasmania: do experiential placements and background influence undergraduate health science student's attitudes toward rural practice? Rural Remote Health. 2008;8(3):962.

22. Brown L, Smith T, Wakely L, Wolfgang R, Little A, Burrows J. Longitudinal tracking of workplace outcomes for undergraduate allied health students undertaking placements in rural Australia. $J$ Allied Health. 2017;46(2):79-87.

23. Sandelowski M. Whatever happened to qualitative description? Res Nurs Health. 2000;23(4):334-340.

24. Sandelowski M. What's in a name? Qualitative description revisited. Res Nurs Health. 2010;33(1):77-84. doi:10.1002/nur.20362

25. Lincoln YS, Guba EG. Naturalistic Inquiry. California: Sage Publishers; 1985.

26. Fatima Y, Kazmi S, King S, Solomon S, Knight S. Positive placement experience and future rural practice intentions: findings from a repeated cross-sectional study. J Multidiscip Healthc. 2018;11:645652. doi:10.2147/JMDH.S178138

27. Critchley J, DeWitt DE, Khan MA, Liaw S. A required rural health module increases students' interest in rural health careers. Rural Remote Health. 2007;7(2):688.

28. Eley DS, Baker PG. Will Australian rural clinical schools be an effective workforce strategy? Early indications of their positive effect on intern choice and rural career interest. Med J Aust. 2007;187(3):166-167.
29. Playford DE, Evans SF, Atkinson DN, Auret KA, Riley GJ. Impact of the Rural Clinical School of Western Australia on work location of medical graduates. Med J Aust. 2014;200(2):104-107.

30. Veitch C, Underhill A, Hays RB. The career aspirations and location intentions of James Cook University's first cohort of medical students: a longitudinal study at course entry and graduation. Rural Remote Health. 2006;6(1):537.

31. Williamson MI, Wilson R, McKechnie R, Ross J. Does the positive influence of an undergraduate rural placement persist into postgraduate years? Rural Remote Health. 2012;12:2011.

32. Wright JR, Bourke L, Waite CJ, et al. A short-term rural placement can change metropolitan medical students' knowledge of, and attitudes to, rural practice. Med J Aust. 2014;201(2):103-105.

33. McAuliffe T, Barnett F. Factors influencing occupational therapy students' perceptions of rural and remote practice. Rural Remote Health. 2009;9:1078. doi:10.22605/RRH1078

34. McAuliffe T, Barnett F. Perceptions towards rural and remote practice: a study of final year occupational therapy students studying in a regional university in Australia. Aust Occup Ther J. 2010;57(5):293300. doi:10.1111/j.1440-1630.2009.00838.x

35. Johnston C, Newstead C, Sanderson M, Wakely L, Osmotherly P. The changing landscape of physiotherapy student clinical placements: an exploration of geographical distribution and student performance across settings. Aust J Rural Health. 2017;25(2):85-93. doi:10.1111/ajr.12302
Journal of Multidisciplinary Healthcare

\section{Publish your work in this journal}

The Journal of Multidisciplinary Healthcare is an international, peerreviewed open-access journal that aims to represent and publish research in healthcare areas delivered by practitioners of different disciplines. This includes studies and reviews conducted by multidisciplinary teams as well as research which evaluates the results or conduct of such teams or healthcare processes in general. The journal

\section{Dovepress}

covers a very wide range of areas and welcomes submissions from practitioners at all levels, from all over the world. The manuscript management system is completely online and includes a very quick and fair peer-review system. Visit http://www.dovepress.com/testimonials. php to read real quotes from published authors. 